\title{
Assessment of the Impact of Trace Elements in FAME Biodiesel on Diesel Oxidation Catalyst Activity after Full Lifetime of Operation in A Heavy-Duty Truck
}

\author{
Jonas Granestrand ${ }^{1, *}$, Rodrigo Suárez París ${ }^{2}$, Marita Nilsson ${ }^{2}$, Francesco Regali ${ }^{2}$ and \\ Lars J. Pettersson ${ }^{1, *}$ \\ 1 Department of Chemical Engineering, KTH Royal Institute of Technology, 10044 Stockholm, Sweden \\ 2 Scania CV, Materials Technology, 15187 Södertälje, Sweden \\ * Correspondence: grane@kth.se (J.G.); lpet@kth.se (L.J.P.)
}

Received: 12 November 2020; Accepted: 7 December 2020; Published: 9 December 2020

\begin{abstract}
Fatty acid methyl ester (FAME) biodiesel contains some trace amounts of Na, K, P, Ca, and Mg. Our objective was to investigate whether the presence of such elements can poison a diesel oxidation catalyst that has been used for an entire regulatory lifetime in a heavy-duty truck fueled by FAME biodiesel. The investigated vehicle-aged catalyst contained high loadings of $\mathrm{S}, \mathrm{P}$, and $\mathrm{Na}$, as well as a visible layer of soot. Activity in the NO oxidation reaction was severely decreased compared to a fresh catalyst of the same type, while the $\mathrm{CO}$ and $\mathrm{C}_{3} \mathrm{H}_{6}$ oxidation reactions were less affected. Subsequent selective trace element removal procedures, followed by activity tests, were used to decouple the effect of different poisons. Sintering was observed to be the main cause of catalyst deactivation. Of the trace elements present on the catalyst, $\mathrm{P}$ had the greatest effect on catalyst activity, while the other trace elements had little effect.
\end{abstract}

Keywords: diesel oxidation catalyst; poisoning; biodiesel; Pt/Pd; phosphorus

\section{Introduction}

Environmental concerns and regulatory pressure have spurred the transport sector to reduce the vehicle emissions of both local pollutants and $\mathrm{CO}_{2}$. The abatement of local pollutants, e.g., nitrogen oxides (NOx) and particulate matter (PM), is achieved with a combination of engine modifications and exhaust aftertreatment equipment, including diesel particulate filters (DPFs) and catalytic treatment units. A schematic of a typical heavy-duty vehicle aftertreatment system is given in Figure 1. Efforts to reduce $\mathrm{CO}_{2}$ emissions include improvements in fuel economy and a gradual shift to renewable fuels, including various biofuels. As an example, different biofuels account for almost $20 \%$ of the energy usage of the Swedish domestic transport sector [1]. Fatty acid methyl ester (FAME) has seen widespread adoption, both as a pure biodiesel fuel (B100) and in blends such as B20 (20\% biodiesel blended with $80 \%$ conventional diesel). However, due to its production process, FAME may contain relatively high levels of $\mathrm{Na}, \mathrm{K}, \mathrm{P}, \mathrm{Ca}$, and $\mathrm{Mg}$. For example EN14214, the European standard for FAME, specifies that B100 may contain up to $5 \mathrm{ppm}$ combined of $\mathrm{Na}$ and $\mathrm{K}$, up to $5 \mathrm{ppm}$ combined of $\mathrm{Ca}$ and $\mathrm{Mg}$, and up to $4 \mathrm{ppm}$ of $\mathrm{P}[2,3]$. $\mathrm{P}$ impurities stem from phospholipids in the biomass used as raw material used for fuel production, $\mathrm{Na}$ and $\mathrm{K}$ stem from the homogenous catalysts commonly used during FAME production, and $\mathrm{Ca}$ and $\mathrm{Mg}$ may be introduced during processing steps such as washing with hard water. These fuel impurities may be deposited on aftertreatment components and affect their effectiveness. It is important to understand how fuel impurities affect catalyst activity to be able to ensure that aftertreatment equipment can remain effective in removing pollutants throughout the entire lifetime of a vehicle. Especially sensitive is the diesel oxidation catalyst (DOC), which is typically 
located at the front of the aftertreatment system and therefore exposed to the highest concentration of impurities.

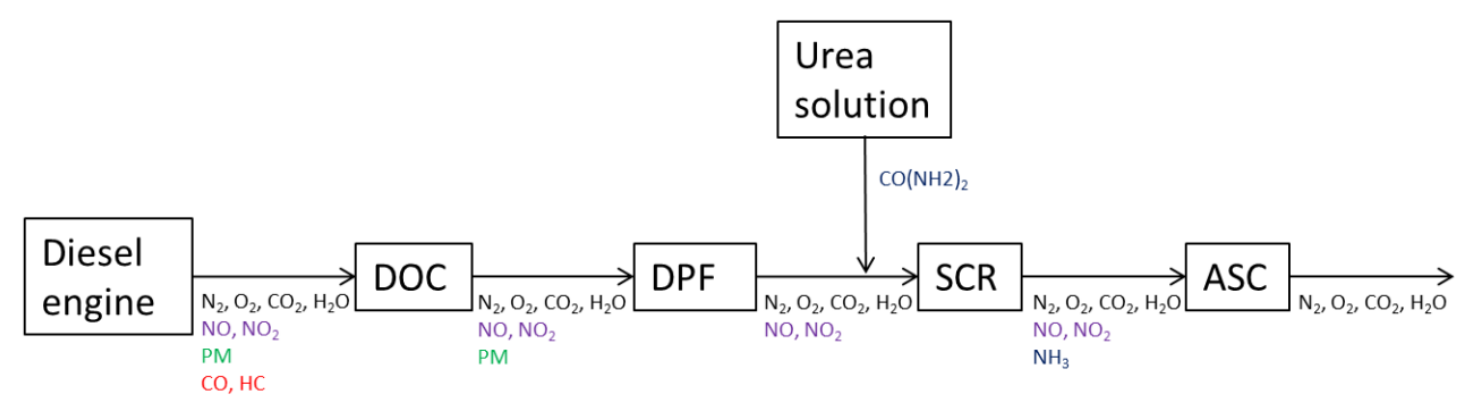

Figure 1. Schematic view of a typical heavy-duty vehicle aftertreatment system. The catalyst investigated in this study was taken from an aftertreatment system with this configuration. DOC: diesel oxidation catalyst; DPF: diesel particulate filter; SCR: selective catalytic reduction catalyst; ASC: ammonia slip catalyst.

In one of the first studies on the effect of $\mathrm{Na}$ on DOC catalyst activity, it was observed that the impregnation of DOCs with as little as $1 \mathrm{wt} \%$ of $\mathrm{Na}$ caused large decreases in $\mathrm{NO}$ and hydrocarbon oxidation activity [4]. However, samples from real vehicles tend to have a non-uniform distribution of poison, with strong penetration concentration gradients throughout the washcoat depth and axially throughout the monolith [2]. Such gradients may not be well-modeled by impregnation, which gives a very uniform distribution of poisons throughout a catalyst monolith. Aging studies using engine test benches more accurately capture the processes in an actual vehicle. Such experiments are typically performed in an accelerated manner, where a poison exposure comparable to the full lifetime of a vehicle can be achieved by increasing the concentration of poison in the fuel. Several such accelerated engine bench aging studies have been performed to study the effect of biodiesel impurities on DOCs [5-8].

Several possible modes of catalyst deactivation may simultaneously occur in a vehicle aftertreatment system, which makes it difficult to isolate the individual effect of each mode of deactivation. Several different fuel impurities may be simultaneously present, as well as impurities originating from lubrication oils. Additionally, high temperatures may lead to thermally-induced catalyst deactivation. The deconvolution of all these different factors, in order to determine how much each contributes to catalyst deactivation, is difficult to achieve. One possible method is to use a protocol with the sequential selective removal of each poison, one by one, with an activity test in between each poison removal step. Such methods have been used to study poisoning from oil additives in conventional diesel vehicles [9-11] to deconvolute the individual poisoning effects of soot, sulfur, and phosphorus. Furthermore, the effect of thermal deactivation can be separated from that of poisoning by considering the fact that poisoning is typically most severe at the DOC monolith inlets, while thermal deactivation is more severe at DOC monolith outlets (due to the proximity to the DPF, which reaches high temperatures during regeneration). Another approach to determine the effect of thermal deactivation is to compare the catalyst activity to that of a fresh catalyst of the same type, after all potential trace elements that may poison the catalyst have been removed. After subjecting a sample to $1000 \mathrm{~h}$ of accelerated engine bench aging with Na-doped B20 fuel, an aging protocol leading to a sodium exposure equivalent to a full vehicle lifetime's operation on B20, Lance et al. [8] used a sequential poison removal protocol to evaluate the individual effects of soot, $\mathrm{P}, \mathrm{S}$, and $\mathrm{Na}$ on DOC activity. A considerable activity improvement in NO oxidation was only observed after the P removal step, indicating that lube-oil-derived phosphorus was the most potent poison present.

Accelerated aging in a test cell allows for considerable savings of time and money compared to analyzing catalysts subjected to a full lifetime in real-world vehicles. However, there is some concern that an accelerated aging procedure may still not completely capture aging in a real sample. 
Indeed, it has been shown [7] that by accelerating the aging too aggressively by using a too highly doped poison concentration in the fuel, deactivation mechanisms not actually observed during real-life aging can be induced. While more time-consuming, analyzing samples from actual vehicles may give more complete and accurate information. Therefore, the objective of our work was to investigate a DOC taken from an actual vehicle that had been in operation for an entire lifetime $(700,000 \mathrm{~km})$ on B100 rape methyl ester (RME) biodiesel. After the vehicle's full lifetime, samples extracted from the inlet and outlet of the DOC, as well as a sample from the front of a DOC aged in an engine cell, were tested in a flow reactor to analyze their activity in the $\mathrm{NO}, \mathrm{CO}$, and $\mathrm{HC}$ reactions. Activity tests were performed following each step of a sequential poison removal protocol in order to assess the effect of each poison present on the catalyst. While studies concerning catalyst deactivation during operation in a vehicle have been published, few such studies have investigated vehicles using FAME biodiesel. To our knowledge, no such study has investigated a catalyst taken from a vehicle that has been in operation for a full regulatory lifetime. As such, our results help clarify the effect of different trace elements in biodiesel on DOC activity and bridge the knowledge gap concerning the different effects of non-accelerated aging in a vehicle compared to accelerated aging in an engine cell.

\section{Results and Discussions}

The trace element contents of the catalyst samples, as determined by X-ray fluorescence (XRF), are shown in Figure 2. The vehicle-aged catalyst contained high loadings of sodium, calcium, phosphorus, and sulfur. S and P were, axially, relatively evenly spread throughout the catalyst, while there was a strong axial gradient for $\mathrm{Na}$ and $\mathrm{Ca}$, with much higher loadings at the front than at the rear. The relatively even axial distribution of $\mathrm{P}$ was different from that observed in many other studies of vehicle-aged samples with un-doped diesel and biodiesel fuel [10-14] and undoped natural gas fuel [15], which instead showed a strong axial gradient in P content. None of the studies cited above had investigated catalysts field-aged for a full lifetime. It is possible that the more even axial distribution observed in this study only occurred after longer aging time, after which the front sections of the catalyst reached equilibrium of adsorbed P. The accelerated cell-aging study by Lance et al. [8] showed an axial distribution of P more similar to that seen in our study. For the cell-aged sample, loadings of $\mathrm{Na}$ and $\mathrm{P}$ were much lower than in the field-aged sample. Only the sulfur content was of a similar magnitude to that at the front of the vehicle-aged sample.

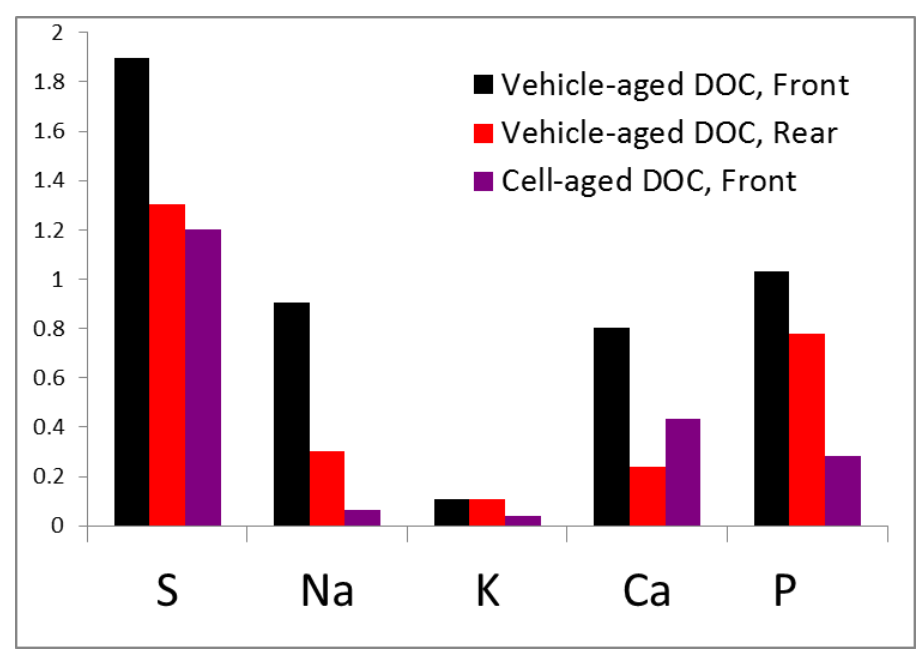

Figure 2. Loading of trace elements in samples taken from the vehicle-aged catalyst (front and rear), as well as in the sample taken from the catalyst aged in an engine cell, as determined by X-ray fluorescence (XRF). 
An XRF analysis showed that, overall, the contaminant removal procedures had the intended results. The contaminant contents, as determined by $\mathrm{XRF}$, after the different selective removal techniques are summarized in Figure 3. As intended, $\mathrm{P}$ was not removed until the acid treatment step, and $\mathrm{Ca}$ and $\mathrm{Na}$ were not removed until the water treatment step. The sulfur removal step was not able to remove all $\mathrm{S}$ in the sample but was selective towards sulfur and did not remove any other contaminants. The oxidative soot removal procedure did not affect the loadings of trace elements. However, a visual inspection showed that the procedure was successful in removing soot. Figure 4 shows a comparison between an as-received vehicle-aged sample and one such sample that had been subjected to the oxidative treatment. A schematic summary of the overall effects of the different removal processes is given in Figure 5.

Table 1. Overview of the procedures used to selectively remove trace elements from the studied catalyst.

\begin{tabular}{|c|c|c|}
\hline Treatment & Conditions & Purpose \\
\hline $4 \mathrm{~h}$ at $400^{\circ} \mathrm{C}$ & $\begin{array}{c}10 \% \mathrm{O}_{2}, 7 \% \mathrm{H}_{2} \mathrm{O}+\text { balance } \mathrm{N}_{2} \text { at a gas hourly space } \\
\text { velocity (GHSV) of } 40,000 \mathrm{~h}^{-1}\end{array}$ & $\begin{array}{l}\text { Removal of adsorbed } \\
\text { hydrocarbons and } \mathrm{H}_{2} \mathrm{O}\end{array}$ \\
\hline $\begin{array}{l}\text { Alternating reductive and } \\
\text { oxidative desulfation at } 600{ }^{\circ} \mathrm{C}\end{array}$ & $\begin{array}{l}5 \text { min reductive followed by } 5 \text { min oxidative for a total of } \\
\qquad 12 \text { times } \\
\text { Reductive: } 1 \% \mathrm{H}_{2}+7 \% \mathrm{H}_{2} \mathrm{O}+\text { balance } \mathrm{N}_{2} \\
\text { Oxidative: } 10 \% \mathrm{O}_{2}+7 \% \mathrm{H}_{2} \mathrm{O}+\text { balance } \mathrm{N}_{2}\end{array}$ & Removal of S \\
\hline De-ionized water wash & $\begin{array}{l}8^{*} 15 \text { min of deionized water washing at } 70^{\circ} \mathrm{C} \text { in an } \\
\text { ultrasound sonicator, followed by } 2 \mathrm{~h} \text { drying at } 100{ }^{\circ} \mathrm{C}\end{array}$ & $\begin{array}{l}\text { Removal of water-soluble } \\
\text { contaminants }\end{array}$ \\
\hline Acid wash & $\begin{array}{l}2 * 1 \mathrm{~h} \text { treatment in an aqueous solution of } 5 \mathrm{wt} \% \text { acetic } \\
\text { acid and } 5 \mathrm{wt} \% \text { oxalic acid at } 70^{\circ} \mathrm{C} \text { in an ultrasound } \\
\text { sonicator, followed by thorough washing with deionized } \\
\text { water and } 2 \mathrm{~h} \text { drying at } 100^{\circ} \mathrm{C}\end{array}$ & $\begin{array}{l}\text { Removal of all remaining } \\
\text { contaminants }\end{array}$ \\
\hline Activity-testing atmosphere & $\begin{array}{l}10 \% \mathrm{O}_{2}, 5 \% \mathrm{CO}_{2}, 5 \% \mathrm{H}_{2} \mathrm{O}, 1000 \mathrm{ppm} \text { of } \mathrm{NO}, 200 \mathrm{ppm} \text { of } \\
\mathrm{CO}, 2 \text { and } 00 \mathrm{ppm} \text { of } \mathrm{C}_{3} \mathrm{H}_{6} \text { and balance } \mathrm{N}_{2} \text { at a GHSV of } \\
80,000 \mathrm{~h}^{-1}\end{array}$ & $\begin{array}{c}\text { Test of catalytic activity after each } \\
\text { removal step }\end{array}$ \\
\hline
\end{tabular}

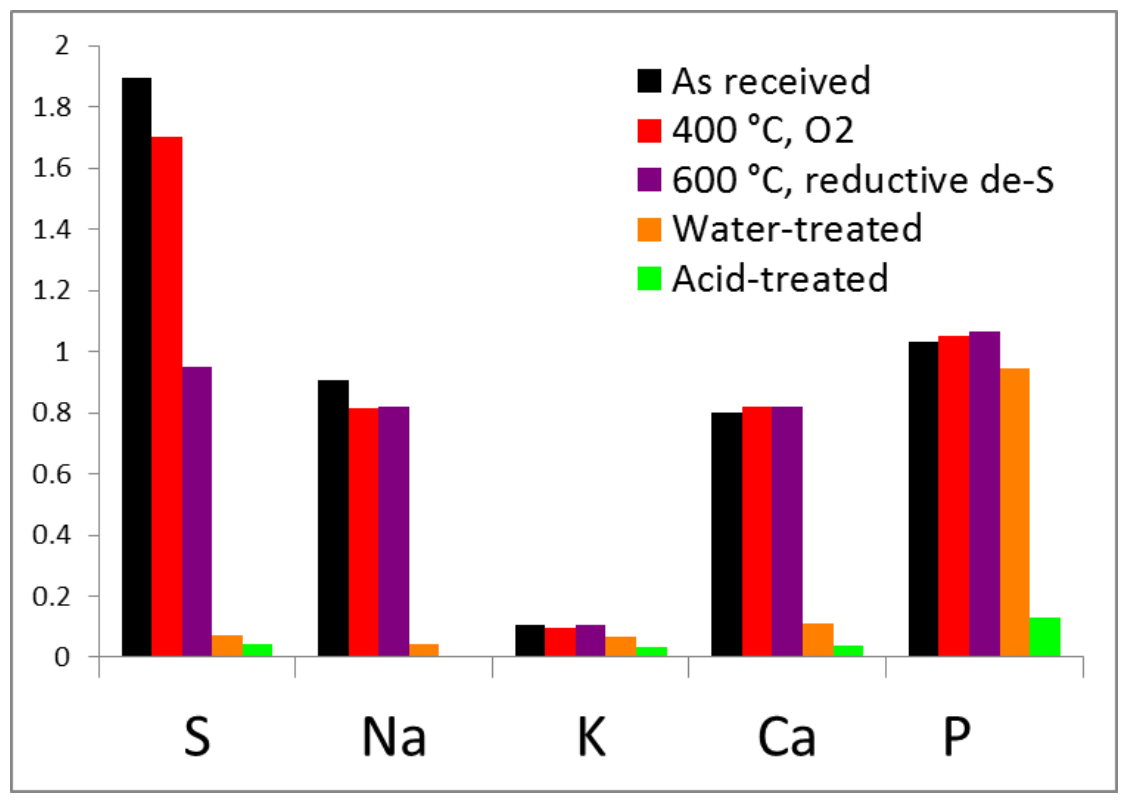

Figure 3. Effect of contaminant removal procedures on contaminant contents, as determined by XRF. The used contaminant removal procedures are described in Table 1. 


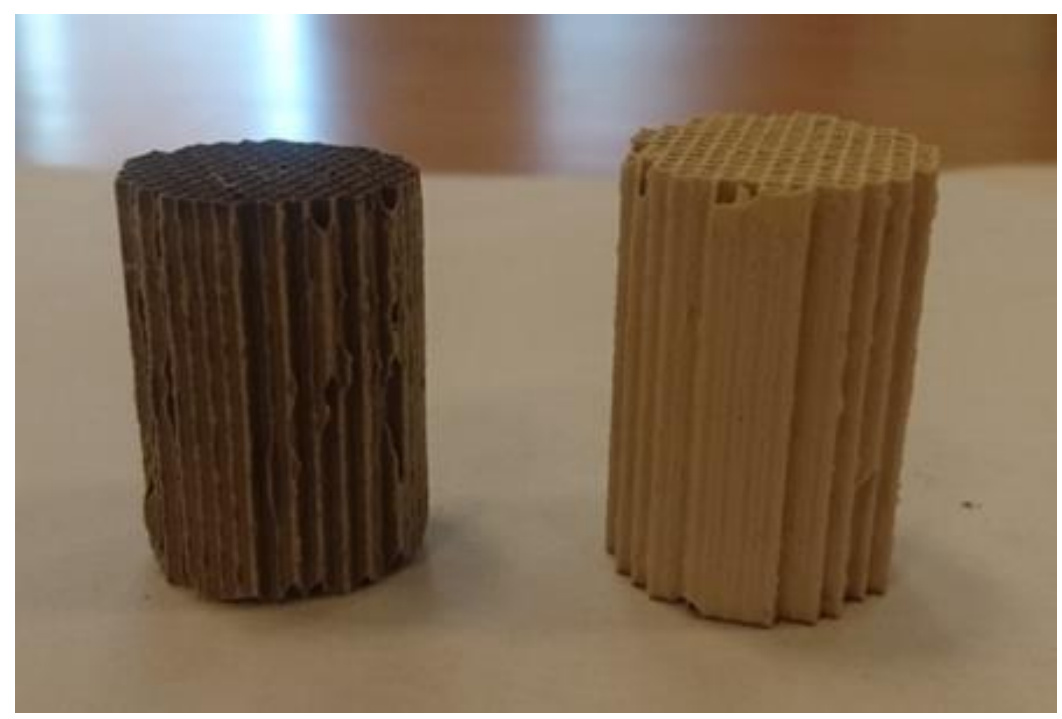

Figure 4. Visual comparison of samples before (left) and after (right) the oxidative soot removal step.

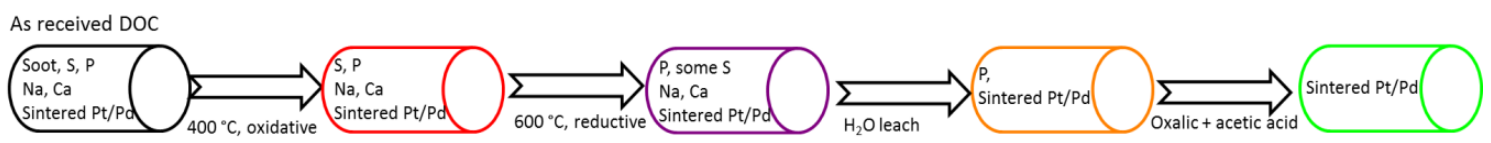

Figure 5. Schematic showing the effect of the contaminant removal procedures on the presence of different trace elements in the DOC.

A comparison of light-off curves between the different as-received samples in the oxidation reactions for CO, propylene, and NO is shown in Figure 6. The cell-aged catalyst was less deactivated than the field-aged catalyst, with $\mathrm{CO}$ and propylene oxidation activities close to that of a fresh catalyst, while the activity in NO oxidation was significantly decreased compared to the fresh sample. The vehicle-aged catalyst was more severely deactivated. Both the sample taken from the front and the sample taken from the rear were significantly deactivated in the $\mathrm{CO}$ and propylene oxidation reactions, and they were severely deactivated in the NO oxidation reaction. The differences in activity between samples taken from the front and from the rear of the vehicle-aged sample were small.

To determine whether the more severe deactivation seen for the vehicle-aged catalyst was caused by the presence of higher loadings of $\mathrm{P}$ and Na compared to the cell-aged sample, activity tests after sequential selective contaminant removal steps were performed for the sample taken from the front of the vehicle-aged catalyst. The effect of the selective contaminant removal procedures on the catalyst activity is shown in Figure 7. Most affected by contaminant removal was the NO oxidation activity. Specifically, a large increase in NO oxidation activity was observed after the acid wash step, which removed $\mathrm{P}$. Even after the removal of $\mathrm{P}$, the catalyst was still considerably deactivated compared to a fresh catalyst. This loss in activity compared to a fresh sample was likely due to thermal deactivation of the catalyst during vehicle operation. $\mathrm{C}_{3} \mathrm{H}_{6}$ and $\mathrm{CO}$ oxidation activities were less affected by trace element removal. Again, the largest effects seemed to have been caused by thermal deactivation. $\mathrm{C}_{3} \mathrm{H}_{6}$ oxidation activity was somewhat recovered after the oxidative treatment, indicating that this reaction was deactivated by the presence of soot. 

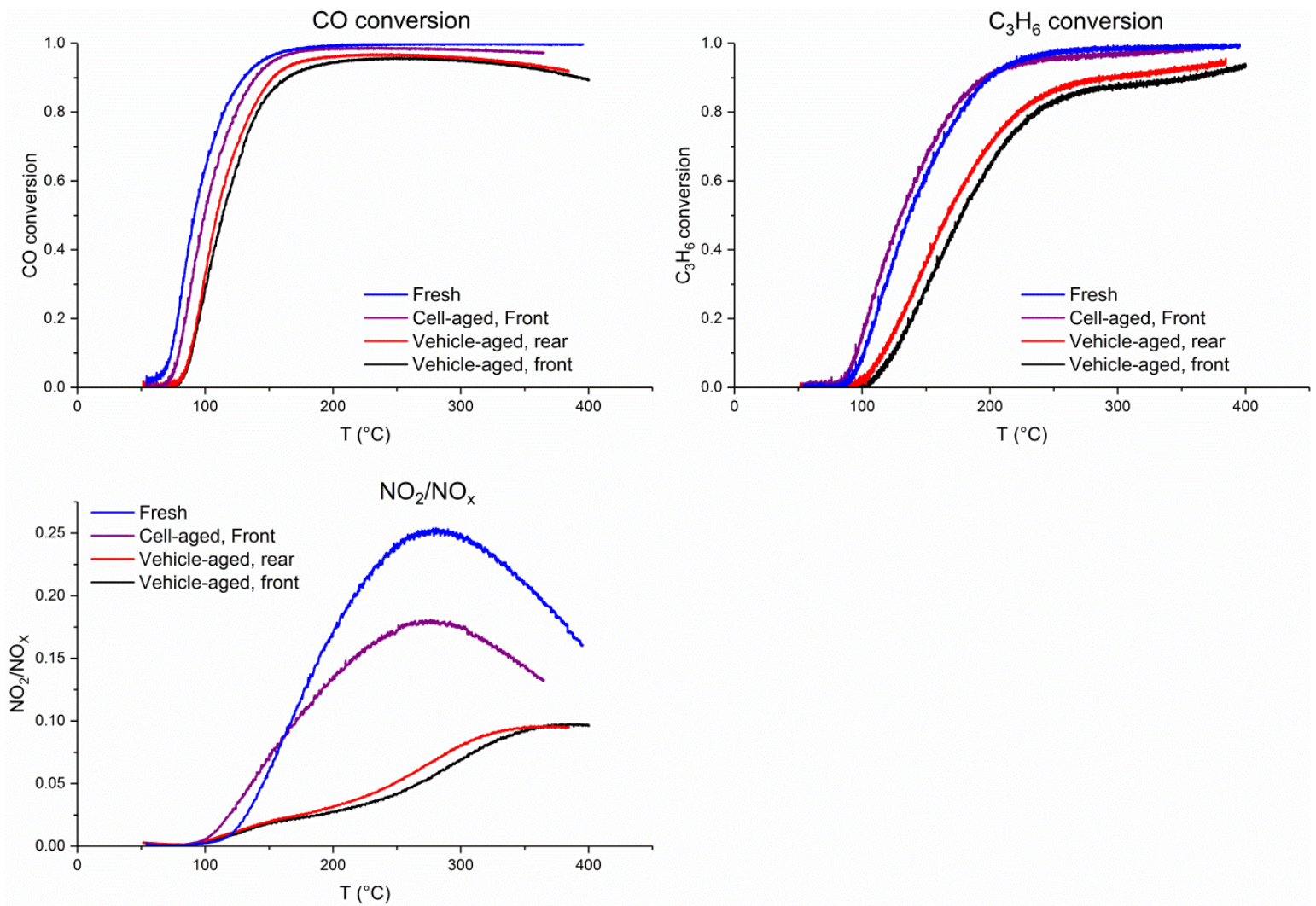

Figure 6. Activity of the samples taken from vehicle-aged catalyst (front and rear) and the cell-aged sample compared to a fresh catalyst of the same type in $\mathrm{CO}$ oxidation, $\mathrm{C}_{3} \mathrm{H}_{6}$ oxidation, and $\mathrm{NO}$ oxidation.
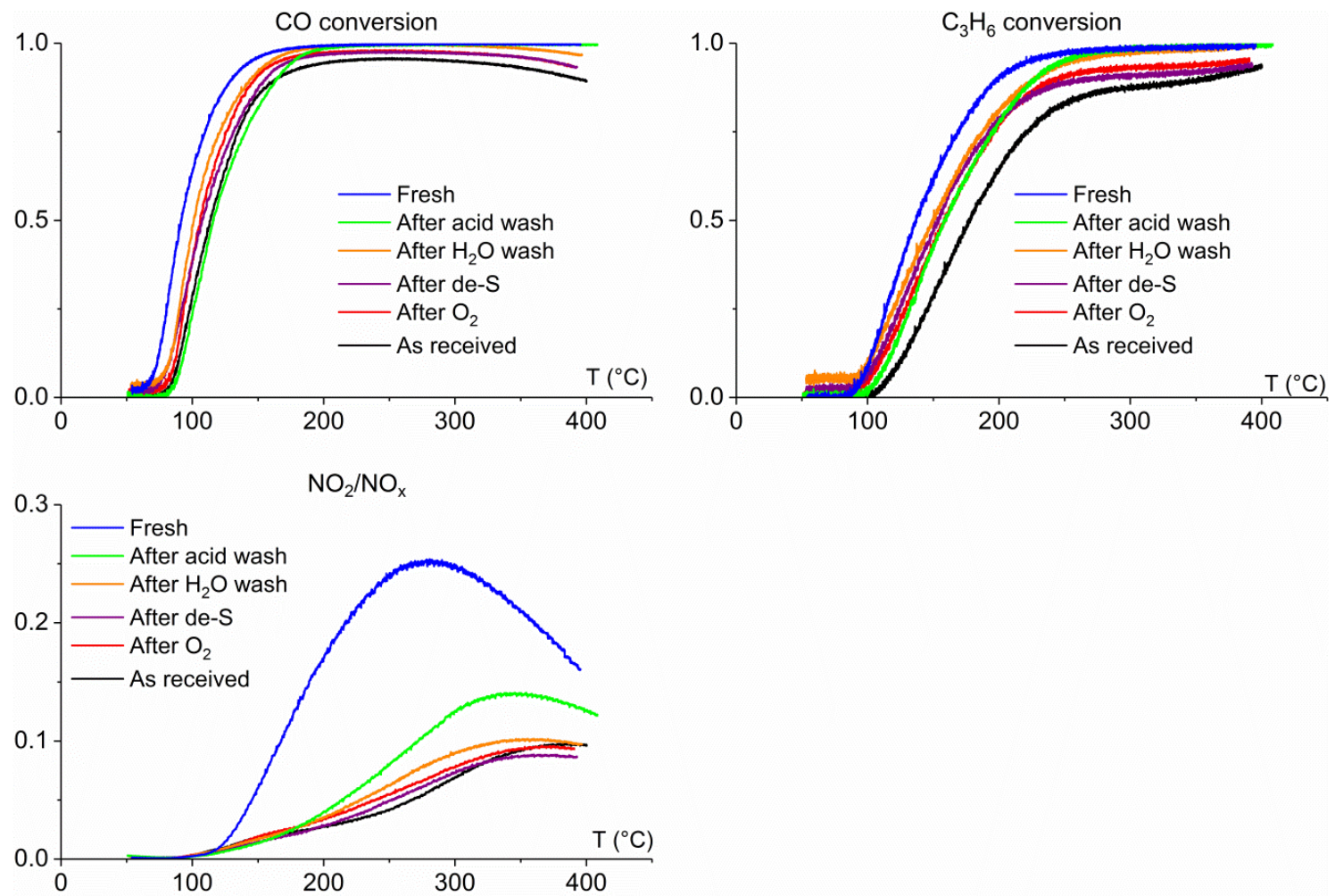

Figure 7. Comparison of the catalytic activity of the sample taken from the front of the vehicle-aged catalyst after the different selective trace element removal steps. 
That $\mathrm{P}$ acted as the most potent poison for the NO oxidation activity while Na had little effect, was in agreement with the study employing accelerated aging in an engine cell with Na-doped biofuel performed by Lance et al. [8]. Kärkkäinen et al. [16] also observed adverse effects of $P$ on DOC catalyst activity after thermal aging during flow-through of a gas mixture containing a vaporized phosphorus salt solution. Both these studies observed a large effect on NO oxidation activity specifically.

One mechanism by which $\mathrm{P}$ has been observed to affect Pt-based diesel oxidation catalysts is by influencing the sintering of the precious metal particles. Studies by Matam et al. $[17,18]$ attributed changes in catalyst activity after the thermal aging of a $\mathrm{Pt} / \mathrm{Al}_{2} \mathrm{O}_{3}$ catalyst in presence of $\mathrm{P}$, deposited in the catalyst via impregnation, to changes in precious metal morphology that were not observed after similar thermal aging in the absence of P. Specifically, Pt particles sintered in the presence of $\mathrm{P}$ were observed to have a more spherical morphology, while Pt particles in samples aged without the presence of $\mathrm{P}$ were more hexagonal in shape and facetted. Such changes in platinum particle morphology may, in turn, affect catalyst activity, as they may affect the distribution of catalyst particle surface planes available for reactants to interact with. Similar changes in precious metal particle morphology have also been observed by Honkanen et al. [19] after thermal aging performed during the flow-through of a gas phase containing a vaporized solution of a phosphorus salt. Their results showed a change in morphology towards more spherical precious metal particles after such aging compared to what was observed after similar thermal aging without the presence of phosphorus. The presence of $\mathrm{P}$ during aging also affected the particle size distribution of metal particles, with slightly larger particles in the samples that had been subjected to $\mathrm{P}$ during thermal aging. The authors observed these effects in monometallic $\mathrm{Pt} / \mathrm{Al}_{2} \mathrm{O}_{3}$ catalysts, as well as in bimetallic $\mathrm{Pt} / \mathrm{Pd} / \mathrm{Al}_{2} \mathrm{O}_{3}$ catalysts. Our results indicated that such morphological changes in $\mathrm{Pt} / \mathrm{Pd}$ particles induced by the presence of $\mathrm{P}$ on their own could not explain the loss of catalyst activity caused by phosphorus. If the main cause of adverse effects of the presence of $\mathrm{P}$ on DOC catalyst activity were morphological changes induced by its presence during sintering, then the catalyst activity would not improve after removing the P content; any changes in $\mathrm{Pt} / \mathrm{Pd}$ particle morphology caused during catalyst particle sintering would remain after $\mathrm{P}$ was removed. Our results indicated that there is a direct chemical interaction between the catalyst particles and the phosphorus present in the catalyst.

In an X-ray absorption spectroscopy study [20] with model Pt/Pd catalysts poisoned with an impregnation method, it was observed that $\mathrm{P}$, in contrast to alkali metals like $\mathrm{Na}$ and $\mathrm{K}$, appeared to electronically interact with $\mathrm{Pt}$ when the samples were subjected to an oxidation reaction atmosphere. In that study, temperature-programmed reduction showed that $\mathrm{Pt}$ in the P-poisoned catalyst sample was less reducible than $\mathrm{Pt}$ in not poisoned catalyst samples and in alkali-metal samples. Furthermore, scanning transmission electron microscopy energy dispersive $\mathrm{X}$-ray spectroscopy (STEM-EDS) imaging showed that while $\mathrm{Na}$ and $\mathrm{K}$ were evenly spread throughout the $\mathrm{Al}_{2} \mathrm{O}_{3}$ support washcoat, $\mathrm{P}$ was preferentially co-located with bimetallic Pt-Pd particles in the catalyst, as opposed to being evenly spread through the $\mathrm{Al}_{2} \mathrm{O}_{3}$ support like $\mathrm{Na}$ and $\mathrm{K}$ [20]. While catalyst samples in that study were artificially poisoned via impregnation, rather than from deposition in the gas phase as would have been the case during use in a vehicle, the study could still help explain the mechanism by which P acts as a poison but $\mathrm{Na}$ does not: unlike sodium, $\mathrm{P}$ seemingly binds to $\mathrm{Pt}-\mathrm{Pd}$ particles and electronically affects their reducibility, which, in turn, affects their catalytic activity.

Such ex-situ and in-situ characterization methods that were used in the study discussed above [20] can be employed in future work to investigate the vehicle-aged samples described in this paper. Electron microscopy and EDS imaging can be used to better understand the location of poisons on vehicle-aged samples, while in-situ spectroscopic techniques can help probe the chemical environment of the catalytically active metals, as well as the specific speciation of poisons. Another avenue for future work is to compare the results of the vehicle-aged samples to those of catalyst samples that have been lab-aged using the deposition of poison salts from aerosols.

The results of the investigation described in this paper can help vehicle manufactures better understand what causes the deactivation of a DOC during the operation of a vehicle, as well as be used 
as input to predict the functional lifetime of their exhaust treatment systems. Furthermore, the key finding that phosphorus has the largest effect on catalyst performance while sodium has little effect has implications for what impurities should have the highest priority to be targeted in fuel upgrading steps during the production of FAME biodiesel.

\section{Materials and Methods}

The investigated catalyst samples were taken from a commercial heavy-duty vehicle that had been in operation using FAME biodiesel for a total mileage of 700,000 km, which is the regulatory lifetime for which EU VI pollutant emission requirements need to be upheld. The vehicle had a DOC-DPF-SCR aftertreatment configuration. As such, the DOC was the aftertreatment equipment component closest to the engine and was thus subjected to relatively high concentrations of impurities. Cylindrical samples (with a diameter of $20 \mathrm{~mm}$ and a length of $30 \mathrm{~mm}$ ) were investigated (see Figure 8). According to XRF analysis, these samples contained high loadings of $\mathrm{P}, \mathrm{S}$, and Na. A sample from a fresh, degreened catalyst was also investigated, as was a sample from the front of a DOC aged in an engine cell for $1100 \mathrm{~h}$ with a total FAME consumption of $71,000 \mathrm{dm}^{3}$. The catalyst formulation was the same in each sample-a bimetallic $\mathrm{Pt} / \mathrm{Pd}$ catalyst on $\mathrm{Al}_{2} \mathrm{O}_{3}$, supported on cordierite monolith.

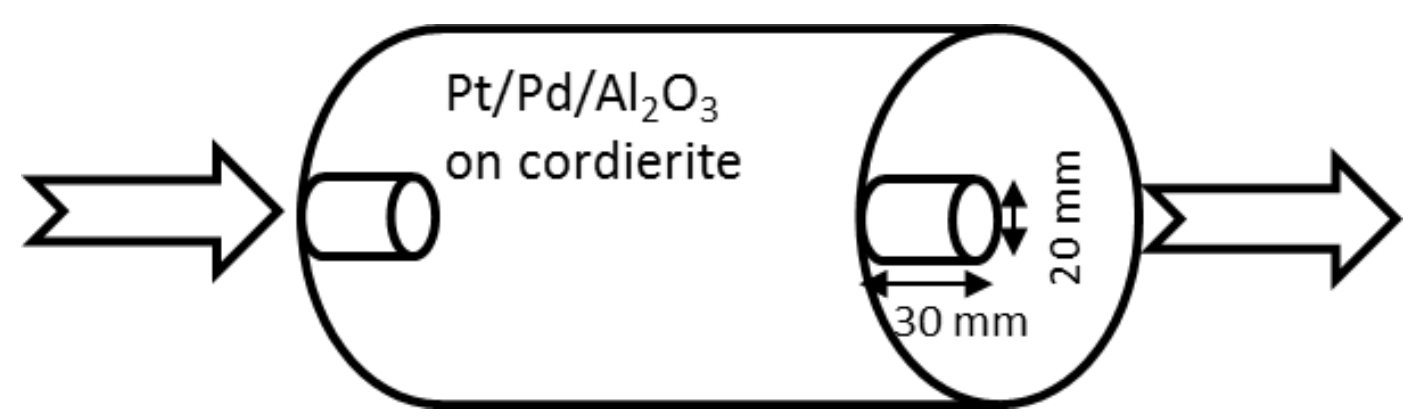

Figure 8. Cylindrical catalyst samples were taken from the front and the rear of the vehicle-aged catalyst.

Catalyst activity tests were performed in a flow reactor, a schematic representation of which can be found in Figure 9. The gas composition was controlled by mass flow controllers and a controlled evaporation mixer from Bronkhorst High-Tech BV. Catalyst samples were placed inside a $25 \mathrm{~mm}$ diameter quartz tube, which was heated in a Carbolite horizontal tubular furnace. During activity tests, the samples were heated to $500{ }^{\circ} \mathrm{C}$ at a nominal heating rate of $5{ }^{\circ} \mathrm{C}$ per minute. The composition of the gas entering the reactor was $10 \% \mathrm{O}_{2}, 5 \% \mathrm{CO}_{2}, 5 \% \mathrm{H}_{2} \mathrm{O}, 1000 \mathrm{ppm}$ of $\mathrm{NO}, 200 \mathrm{ppm}$ of $\mathrm{CO}, 200 \mathrm{ppm}$ of $\mathrm{C}_{3} \mathrm{H}_{6}$, and balance $\mathrm{N}_{2}$ (on volumetric basis). During the temperature ramp, the conversion in the $\mathrm{CO}$, $\mathrm{NO}$, and $\mathrm{C}_{3} \mathrm{H}_{6}$ oxidation reactions was measured continuously by an MKS FTIR instrument. The gas hourly space velocity (GHSV) during activity testing was $80,000 \mathrm{~h}^{-1}$. The temperature of the catalyst samples during activity testing was measured with a $1 \mathrm{~mm}$ type $\mathrm{K}$ thermocouple located in the radial middle of the reactor tube, $3 \mathrm{~mm}$ in front of the catalyst samples.

To test the effects of the presence of each of the trace element contaminants, individual contaminants were removed using consecutive selective contaminant removal procedures, an approach based on the work by Lance et al. [8] The details of the procedures, as well as their intended purpose, are summarized in Table 1. After each subsequent contaminant removal step, the samples' catalytic activities were tested in the flow reactor.

To confirm that the catalyst treatment procedures had the intended effect of selectively removing contaminants, additional samples from the vehicle-aged DOC's front were subjected to the treatment steps described in Table 1, followed by an elemental analysis by XRF. XRF analyses were performed for an as-received sample; a sample submitted only to oxidative treatment at $400{ }^{\circ} \mathrm{C}$; a sample submitted to oxidative treatment at $400{ }^{\circ} \mathrm{C}$, then desulfation at $600^{\circ} \mathrm{C}$, and so on; and a final sample for XRF analysis that underwent all of the sequential removal steps. The process is described schematically in Figure 10. In each case, $3.2 \mathrm{~g}$ of the sample was ground into a fine powder by ball milling, mixed with 
$0.8 \mathrm{~g}$ of the $\mathrm{C} 38 \mathrm{H} 76 \mathrm{~N} 2 \mathrm{O} 2$ binder, and pressed into a briquette. $\mathrm{XRF}$ analysis was then performed on the briquettes in a PANalytical, Epsilon3 XL XRF instrument.

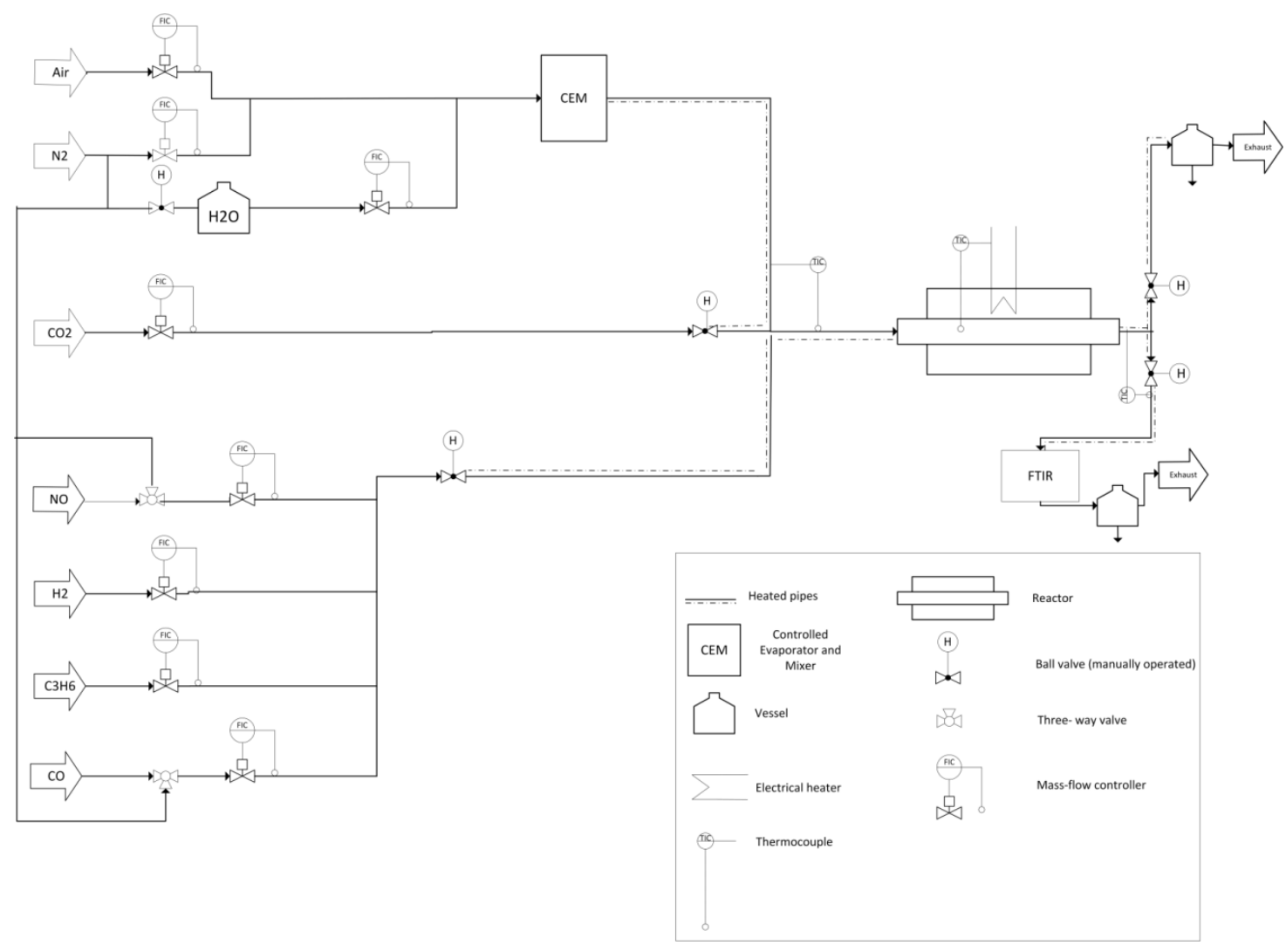

Figure 9. Schematic of the flow reactor used for activity testing.

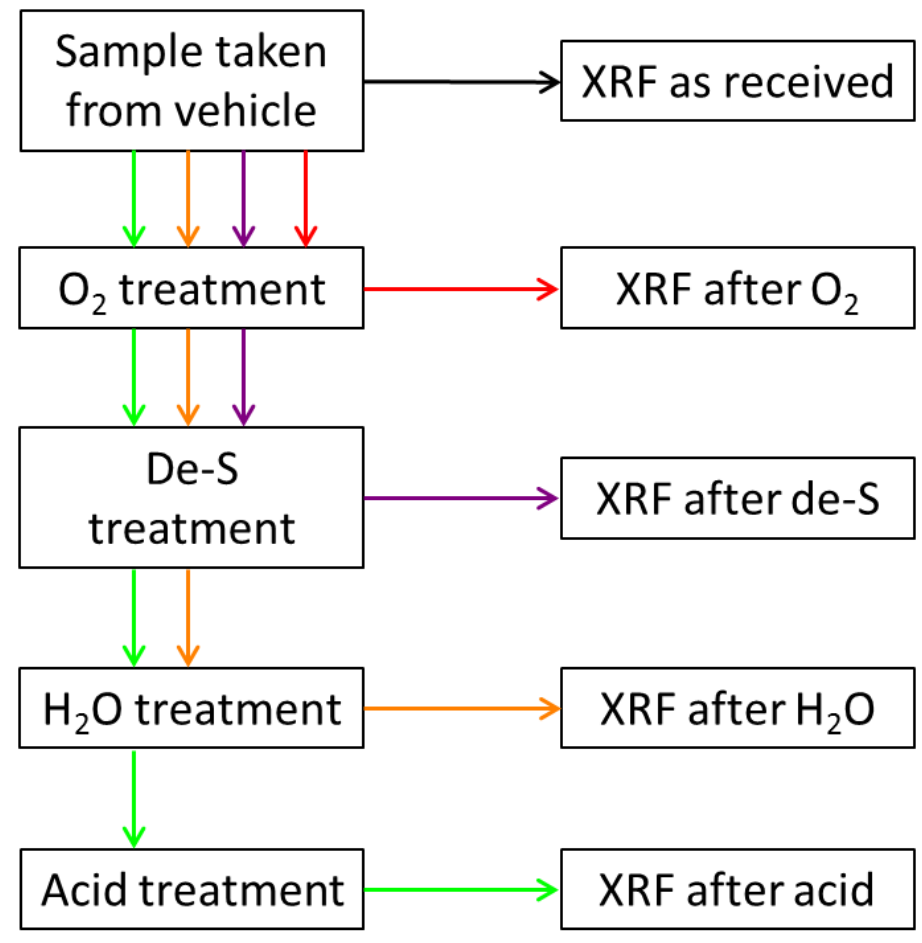

Figure 10. Schematic overview of the treatments undergone by the samples analyzed by XRF to confirm that the contaminant removal procedures had the intended effect. 


\section{Conclusions}

To investigate the effect of FAME biodiesel impurities on DOC activity, a catalyst that had been used for an entire regulatory lifetime in a heavy-duty vehicle powered by B100 FAME biodiesel was studied. The tests revealed that the DOC was heavily deactivated. Specifically, it was severely deactivated in the $\mathrm{NO}$ oxidation reaction and somewhat deactivated in the $\mathrm{C}_{3} \mathrm{H}_{6}$ oxidation reaction. Deactivation in the $\mathrm{CO}$ oxidation reaction was less significant. Samples both from the front and rear of the catalyst were examined, and their performance was similar. Activity testing after selective contaminant removal procedures, as well as a comparison with a fresh catalyst of the same type, showed that phosphorus was the most impactful poison of the trace elements present on the catalyst, while sodium and calcium had little effect. However, thermal deactivation appeared to more severely affect the catalyst activity than did the presence of poisons. The aftertreatment system overall adhered to regulations despite this severely deactivated DOC. This was likely achieved due to the presence of oxidizing catalyst in the DPF.

Author Contributions: Conceptualization, J.G.; methodology, J.G.; validation, J.G.; investigation, J.G.; resources, R.S.P., M.N., F.R., and L.J.P.; data curation, J.G. and L.J.P.; writing—original draft preparation, J.G.; writing-review and editing, J.G., M.N., and L.J.P.; visualization, J.G.; supervision, R.S.P., M.N., F.R., and L.J.P.; project administration, R.S.P., M.N., F.R., and L.J.P.; funding acquisition, M.N. and L.J.P. All authors have read and agreed to the published version of the manuscript.

Funding: This research was funded by the Swedish Energy Agency, grant number 37178-1.

Conflicts of Interest: The authors declare no conflict of interest. The funders had no role in the design of the study; in the collection, analyses, or interpretation of data; in the writing of the manuscript, or in the decision to publish the results.

\section{References}

1. The Swedish Petroleum \& Biofuels Institute. SPBI Branschfakta 2019; The Swedish Petroleum \& Biofuels Institute: Stockholm, Sweden, 2019.

2. Granestrand, J.; Dahlin, S.; Immele, O.; Schmalhorst, L.; Lantto, C.; Nilsson, M.; París, R.S.; Regali, F.; Pettersson, L.J. Catalytic aftertreatment systems for trucks fueled by biofuels-Aspects on the impact of fuel quality on catalyst deactivation. In RSC Catalysis; The Royal Society of Chemistry: London, UK, 2018; Volume 30, pp. 64-145. [CrossRef]

3. Jääskeläinen, H. Biodiesel Standards \& Properties. Available online: https://www.dieselnet.com/tech/fuel_ biodiesel_std.php (accessed on 23 September 2020).

4. Cavataio, G.; Jen, H.-W.; Dobson, D.A.; Warner, J.R. Laboratory Study to Determine Impact of Na and K Exposure on the Durability of DOC and SCR Catalyst Formulations, SAE 2009-01-2823. Presented at the SAE 2009 Powertrains Fuels and Lubricants Meeting, Florence, Italy, 15-17 June 2009. [CrossRef]

5. Brookshear, D.W.; Lance, M.J.; McCormick, R.L.; Toops, T.J. Investigations of the impact of biodiesel metal contaminants on emissions control devices. In RSC Catalysis; The Royal Society of Chemistry: London, UK, 2017; Volume 29, pp. 317-342. [CrossRef]

6. Williams, A.; Burton, J.; McCormick, R.L.; Toops, T.; Wereszczak, A.A.; Fox, E.E.; Lance, M.J.; Cavataio, G.; Dobson, D.; Warner, J.; et al. Impact of Fuel Metal Impurities on the Durability of a Light-Duty Diesel Aftertreatment System, SAE 2013-01-0513. Presented at the SAE 2013 World Congress and Exhibition, Detroit, MI, USA, 16-18 April 2013. [CrossRef]

7. Williams, A.; McCormick, R.; Lance, M.; Xie, C.; Toops, T.; Brezny, R. Effect of Accelerated Aging Rate on the Capture of Fuel-Borne Metal Impurities by Emissions Control Devices. SAE Int. J. Fuels Lubr. 2014, 7, 471-479. [CrossRef]

8. Lance, M.; Wereszczak, A.A.; Toops, T.J.; Ancimer, R.; An, H.; Li, J.; Rogoski, L.; Sindler, P.; Williams, A.; Ragatz, A.; et al. Evaluation of fuel-borne sodium effects on a DOC-DPF-SCR heavy-duty engine emission control system: Evaluation of full-useful life, SAE 2016-01-2322. SAE Int. J. Fuels Lubr. 2016, 9, 683-694. [CrossRef] 
9. Beutel, T.; Dettling, J.; Hollobaugh, D.; Kumar, S.; Mueller, T. The Demands on DOC Technology in Advanced Euro-IV/V Applications, SAE 2005-26-021. Presented at the 2005 Symposium on International Automotive Technology, Pune, India, 19-22 January 2005. [CrossRef]

10. Wiebenga, M.H.; Kim, C.H.; Schmieg, S.J.; Oh, S.H.; Brown, D.B.; Kim, D.H.; Lee, J.-H.; Peden, C.H.F. Deactivation mechanisms of Pt/Pd-based diesel oxidation catalysts. Catal. Today 2012, 184, 197-204. [CrossRef]

11. Li, J.; Szailer, T.; Watts, A.; Currier, N.; Yezerets, A. Investigation of the Impact of Real-World Aging on Diesel Oxidation Catalysts, SAE 2012-01-1094. SAE Int. J. Engines 2012, 5, 985-994. [CrossRef]

12. Cabello Galisteo, F.; Mariscal, R.; López Granados, M.; Fierro, J.L.G.; Brettes, P.; Salas, O. Reactivation of a Commercial Diesel Oxidation Catalyst by Acid Washing. Environ. Sci. Technol. 2005, 39, 3844-3848. [CrossRef] [PubMed]

13. Andersson, J.; Antonsson, M.; Eurenius, L.; Olsson, E.; Skoglundh, M. Deactivation of diesel oxidation catalysts: Vehicle- and synthetic aging correlations. Appl. Catal. B 2007, 72, 71-81. [CrossRef]

14. Lanzerath, P.; Guethenke, A.; Massner, A.; Gaertner, U. Analytical investigations on ageing phenomena of catalytic exhaust gas aftertreatment components. Catal. Today 2009, 147, S265-S270. [CrossRef]

15. Honkanen, M.; Kärkkäinen, M.; Viitanen, V.; Jiang, H.; Kallinen, K.; Huuhtanen, M.; Vippola, M.; Lahtinen, J.; Keiski, R.; Lepistö, T. Structural Characteristics of Natural-Gas-Vehicle-Aged Oxidation Catalyst. Top. Catal. 2013, 56, 576-585. [CrossRef]

16. Kärkkäinen, M.; Kolli, T.; Honkanen, M.; Heikkinen, O.; Huuhtanen, M.; Kallinen, K.; Lepistö, T.; Lahtinen, J.; Vippola, M.; Keiski, R.L. The Effect of Phosphorus Exposure on Diesel Oxidation Catalysts-Part I: Activity Measurements, Elementary and Surface Analyses. Top. Catal. 2015, 58, 961-970. [CrossRef]

17. Matam, S.K.; Kondratenko, E.V.; Aguirre, M.H.; Hug, P.; Rentsch, D.; Winkler, A.; Weidenkaff, A.; Ferri, D. The impact of aging environment on the evolution of $\mathrm{Al} 2 \mathrm{O} 3$ supported Pt nanoparticles and their NO oxidation activity. Appl. Catal. B 2013, 129, 214-224. [CrossRef]

18. Matam, S.K.; Winkler, A.; Weidenkaff, A.; Ferri, D. Observations on the Aging Environment Dependent NO Oxidation Activity of Model Pt/Al2O3 Diesel Oxidation Catalyst. Top. Catal. 2013, 56, 329-332. [CrossRef]

19. Honkanen, M.; Kärkkäinen, M.; Heikkinen, O.; Kallinen, K.; Kolli, T.; Huuhtanen, M.; Lahtinen, J.; Keiski, R.L.; Lepistö, T.; Vippola, M. The Effect of Phosphorus Exposure on Diesel Oxidation Catalysts-Part II: Characterization of Structural Changes by Transmission Electron Microscopy. Top. Catal. 2015, 58, 971-976. [CrossRef]

20. Bergman, S.L.; Granestrand, J.; Xi, S.; Du, Y.; Tang, Y.; Tang, C.; Kienkas, L.; Pettersson, L.J.; Bernasek, S.L. Probing the Oxidation/Reduction Dynamics of Fresh and P-, Na-, and K-Contaminated Pt/Pd/Al2O3 Diesel Oxidation Catalysts by STEM, TPR, and in Situ XANES. J. Phys. Chem. C 2020, 124, 2945-2952. [CrossRef]

Publisher's Note: MDPI stays neutral with regard to jurisdictional claims in published maps and institutional affiliations.

(C) 2020 by the authors. Licensee MDPI, Basel, Switzerland. This article is an open access article distributed under the terms and conditions of the Creative Commons Attribution (CC BY) license (http://creativecommons.org/licenses/by/4.0/). 